\title{
COVID-19 and publishing
}

\author{
Kihong Kim \\ Department of Physics, Ajou University, Suwon, Korea
}

Currently, coronavirus disease 2019 (COVID-19) is sweeping across the entire world and no one is free from its influence. All people involved in the publishing of scholarly journals including researchers, reviewers, editors, and publishers work in environments that differ significantly from those of the pre-COVID-19 era. Recently, a number of editorials and essays on how journal editors should cope with this situation have been published [1-3]. Many have expressed the opinion that research papers directly related to COVID-19 should be published as promptly as possible, though it is necessary to maintain the high quality of the peer review process. In addition, it has been suggested that more flexibility in the editorial procedure, such as relaxing the requirements for the author's revision and allowing more time to review, is desired. For obvious reasons, the number of research papers on COVID-19 has increased explosively, causing considerable difficulties for editors of related journals. However, it seems that until now, there has been no significant change in the number of papers in other scientific fields.

Due to COVID-19, many people are forced to work from home and do a lot of work online. Classes, exams, seminars, conferences, and business meetings are held online around the world. From this experience, I guess many of us have realized that a substantial part of those activities can be done more efficiently in this way. Even after COVID-19 has passed, I expect that a lot of human social activities will be changed irreversibly and rely much more on online activities than before. Such a transition will touch on all stages of writing and publishing of scientific papers. It is certain that technologies for online communication, virtual reality, artificial intelligence, and online security will evolve rapidly to make online activities more reliable in the future.

In the forthcoming issues of Science Editing, we plan to publish articles on various aspects of the impact of COVID-19 on scholarly publishing. In this issue, three interesting articles are published. The article by Chung et al. [4] presents and discusses the results of the survey of journal editors and staffs regarding how they assess the current and future situation of editing

Received: August 12, 2020 Accepted: August 12, 2020

Correspondence to Kihong Kim khkim@ajou.ac.kr

ORCID

Kihong Kim

https://orcid.org/0000-0001-9965-3535 and publishing in the time of the COVID-19 pandemic. This survey was conducted by the Korean Council of Science Editors and the Council of Asian Science Editors and all respondents were from Asian countries including Korea, Indonesia, Vietnam, and Malaysia. Most of the respondents are affiliated with universities and serve as editors of local society journals. The article by Oh and Kim [5] presents a bibliometric analysis of COVID-19-related papers published in the field of nursing and the essay by Oh [6] discusses some experience of the impact of COVID-19 on journal editing. In the future, we will continue to publish interesting articles on 
topics such as the influence of COVID-19 on the research productivity of scientists, bibliographic analyses of COVID19-related papers published in various academic fields, and the experiences and opinions of editors and researchers from around the world. I hope all readers of Science Editing will go through these difficult times well and stay healthy.

\section{Conflict of Interest}

Kihong Kim has been the editor of Science Editing since 2014.

\section{References}

1. Bauchner H, Fontanarosa PB, Golub RM. Editorial evaluation and peer review during a pandemic: how journals maintain standards. JAMA 2020;324:453-4. https://doi. org/10.1001/jama.2020.11764
2. Bazdaric K, Smart P. ESE and EASE call for high standards of research and editing. Eur Sci Ed 2020;46:e53230. https:// doi.org/10.3897/ese.2020.e53230

3. Eisen MB, Akhmanova A, Behrens TE, Weigel D. Publishing in the time of COVID-19. eLife 2020;9:e57162. https:// doi.org/10.7554/eLife.57162

4. Chung Y, Kim S, Huh S. Influence of the COVID-19 pandemic on Asian scholarly journal editors' daily life, work, and opinions on future journal development. Sci Ed 2020;7:111-7. https://doi.org/10.6087/kcse.204

5. Oh J, Kim A. A bibliometric analysis of COVID-19 research published in nursing journals. Sci Ed 2020;7:11824. https://doi.org/10.6087/kcse.205

6. Oh S. Impact of COVID-19 to the duration of the peer review process of the Journal of Animal Science and Technology. Sci Ed 2020;7:198-200. https://doi.org/10.6087/ kcse.218 